\title{
Thyroid hormone stimulates basal and interleukin (IL)-1-induced IL-6 production in human bone marrow stromal cells: a possible mediator of thyroid hormone-induced bone loss
}

\author{
C-H Kim, H-K Kim, Y K Shong, K-U Lee and G S Kim \\ Division of Endocrinology, Asan Medical Center, University of Ulsan College of Medicine, Seoul, Korea \\ (Requests for offprints should be addressed to G S Kim, Division of Endocrinology, Asan Medical Center, Song-Pa, PO Box 145, Seoul 138-600, Korea) \\ (C-H Kim is now at Department of Internal Medicine, Soonchunhyang University College of Medicine, Seoul, Korea) \\ (H-K Kim is now at Department of Internal Medicine, Gil Medical Center, Gachon Medical College, Inchon, Korea)
}

\begin{abstract}
It is well known that excessive thyroid hormone in the body is associated with bone loss. However, the mechanism by which thyroid hormone affects bone turnover remains unclear. It has been shown that it stimulates osteoclastic bone resorption indirectly via unknown mediators secreted by osteoblasts. To determine if interleukin-6 (IL-6) or interleukin-11 (IL-11) could be the mediator(s) of thyroid hormone-induced bone loss, we studied the effects of 3,5, $3^{\prime}$-tri-iodothyronine $\left(\mathrm{T}_{3}\right)$ on basal and interleukin-1 (IL-1)-stimulated IL-6/IL-11 production in primary cultured human bone marrow stromal cells. $\mathrm{T}_{3}$ at $10^{-12}-10^{-8} \mathrm{M}$ concentration significantly
\end{abstract}

increased basal IL-6 production in a dose-dependent manner. It also had an additive effect on IL-1-stimulated IL-6 production, but failed to elicit a detectable effect on basal or IL-1-stimulated IL-11 production. Treatment with $17 \beta$-estradiol $\left(10^{-8} \mathrm{M}\right)$ did not affect the action of $\mathrm{T}_{3}$ on IL-6/IL-11 production. These results suggest that thyroid hormone may stimulate bone resorption by increasing basal and IL-1-induced IL-6 production from osteoblast-lineage cells, and these effects are independent of estrogen status.

Journal of Endocrinology (1999) 160, 97-102

\section{Introduction}

It has been established that excessive thyroid hormone in the body is associated with bone loss. Bone mass is reduced in patients with hyperthyroidism or receiving long-term thyroid hormone suppression therapy (Toh et al. 1985, Diamond et al. 1991, Allain \& McGregor 1992), and individuals with a history of thyrotoxicosis have an increased risk of fracture (Cummings et al. 1995). Studies on biochemical markers (Lee et al. 1990, Harvey et al. 1991) and bone histomorphometry (Bordier et al. 1967, Mundy et al. 1976, Mosekilde \& Melsen 1978) showed increased bone turnover in thyrotoxic patients, suggesting that predominantly osteoclastic activity is responsible for the bone loss in thyrotoxicosis. However, the exact mechanism by which thyroid hormone stimulates bone resorption remains unclear.

It has been shown that thyroid hormone directly stimulates bone resorption in organ culture of neonatal mouse calvaria (Klaushofer et al. 1989) and fetal rat limb bones (Mundy et al. 1976, Hoffmann et al. 1986). Thyroid hormone receptors have been demonstrated in osteoblastic cell lines such as ROS $17 / 2 \cdot 8$ (Rizzoli et al. 1986), UMR-106 (LeBron et al. 1989) and MC3T3-El (Kasono et al. 1988), and direct effects of tri-iodothyronine $\left(\mathrm{T}_{3}\right)$ on proliferation and differentiation of human osteoblast-like cells have also been documented (Kassem et al. 1993). In contrast, there has been a paucity of data on the direct functional effects of thyroid hormone on osteoclasts, despite a report that human osteoclastoma cells express $T_{3}$ receptors (Allain et al. 1996). Previous studies suggested that the action of $\mathrm{T}_{3}$ on bone is mediated by osteoblasts. Allain et al. (1992) and Britto et al. (1994) showed that $T_{3}$ stimulated osteoclastic bone resorption in the presence of osteoblasts, but not in their absence. Furthermore, stimulation of resorption also occurred if osteoblasts were pretreated with $\mathrm{T}_{3}$ and then osteoblast-osteoclast coculture was carried out in the absence of $\mathrm{T}_{3}$. These findings imply that thyroid hormone indirectly stimulates osteoclasts via a mediator produced by osteoblasts. However, the mediator responsible for the activation of osteoclasts by thyroid hormone has yet to be elucidated.

Osteoblasts and bone marrow stromal cells produce bone-active cytokines such as interleukin-6 (IL-6) and interleukin-11 (IL-11) which are critical for osteoclast formation and bone resorption (Manolagas 1995, Girasole et al. 1992, 1994). These cytokines have been suggested to mediate the effects of many stimulators of bone resorption such as parathyroid hormone, interleukin-1, and tumor necrosis factor- $\alpha$. On the basis of these studies, it can be 
postulated that thyroid hormone stimulates IL-6 and/ or IL-11 production by osteoblastic cells, resulting in increased bone resorption. To test this hypothesis, we examined the effects of thyroid hormone on basal and IL-1-stimulated IL-6 and IL-11 production in primary cultured human bone marrow stromal cells (hBMSCs). In addition, we investigated the possible influence of estrogen on thyroid hormone action.

\section{Materials and Methods}

\section{Materials}

3,5,3'-Tri-iodothyronine $\left(\mathrm{T}_{3}\right), \quad 3,3^{\prime}, 5^{\prime}$-tri-iodothyronine (reverse $\mathrm{T}_{3}, \mathrm{rT}_{3}$ ), recombinant human IL-1 $\alpha$ and $\alpha$-modified minimum essential medium $(\alpha-M E M)$ were purchased from Sigma Chemical Co. (St Louis, MO, USA). IL-6 ELISA kits were obtained from Genzyme (Cambridge, MA, USA), and IL-11 ELISA kits from R\&D Systems (Minneapolis, MN, USA). The detection limits of IL-6 and IL-11 assays were 18 and $8 \mathrm{pg} / \mathrm{ml}$, and coefficients of variation were 9.5 and $8.9 \%$ respectively.

\section{hBMSC culture}

hBMSCs were isolated from ribs discarded at the time of open thoracotomy as described previously (Kim et al. 1996, 1997b). None of the patients from whom the ribs were obtained had metabolic bone disease, thyroid disease, or were taking thyroid hormone. Briefly, the ribs were excised aseptically, cleaned of soft tissues, and opened longitudinally. The exposed bone marrow was flushed out using several washes of serum-free $\alpha$-MEM. The medium with flushed bone marrow was centrifuged at 1400 r.p.m. for $10 \mathrm{~min}$. Cell pellets were resuspended in culture medium, and enriched bone marrow stromal cells were obtained by Ficoll/Hypaque (specific gravity 1.077 ) gradient centrifugation. The cells were seeded into a $75 \mathrm{~cm}^{2}$ plastic culture flask at a density of $4 \times 10^{5}$ cells $/ \mathrm{cm}^{2}$ and cultured in $\alpha$-MEM containing $10 \%$ fetal bovine serum, penicillin and streptomycin $(100 \mathrm{U} / \mathrm{ml}$ and $100 \mu \mathrm{g} / \mathrm{ml}$ respectively). The medium was changed twice weekly from the second week, and when the cells were grown to $80 \%$ confluence, they were then subcultured using $0 \cdot 01 \%$ trypsin and $0.05 \%$ EDTA. The second-passage cells were used for the experiments.

\section{Effect of $T_{3}$ on basal IL-6 and IL-11 production by} hBMSCs

$\mathrm{T}_{3}$ and $\mathrm{rT}_{3}$ were dissolved in ethanol and the initial $10^{-5} \mathrm{M}$ stock solution was serially diluted to concentrations of between $10^{-8} \mathrm{M}$ and $10^{-12} \mathrm{M}$. The vehicle was added to control cultures, and the final concentration of ethanol in the culture medium did not exceed $0 \cdot 1 \%$.
The cells $\left(3 \times 10^{4} /\right.$ well $)$ were subcultured in a 48 -well plate containing $\alpha$-MEM and 5\% charcoal-stripped serum for 2 days. Subsequently, the medium was replaced with fresh medium containing various doses of $\mathrm{T}_{3}\left(10^{-12}\right.$ $\left.10^{-8} \mathrm{M}\right)$ or $\mathrm{rT}_{3}\left(10^{-8} \mathrm{M}\right)$, and then cultured for an additional $72 \mathrm{~h}$. After $72 \mathrm{~h}$, the conditioned medium was collected, centrifuged free of cell debris, and stored at $-20{ }^{\circ} \mathrm{C}$ until IL-6 and IL-11 assay. The concentration of IL-6 and IL-11 in the medium was measured by ELISA using commercial kits. The number of cells in each well was determined by quadruplicate hemocytometer counts of trypsin-EDTA-released cells at the end of the culture. Data are expressed as the amount of IL-6 or IL-11 produced per $10^{5}$ cells.

\section{Effect of $T_{3}$ on IL-1-stimulated IL-6 and IL-11 production by hBMSCs}

Cells were seeded into a 48-well plate, cultured as described above, and treated with various doses of IL-1 (10, $100,1000 \mathrm{U} / \mathrm{ml}$ ) with or without the addition of $\mathrm{T}_{3}$ $\left(10^{-8} \mathrm{M}\right)$. Then the amounts of IL-6 and IL-11 produced in the subsequent $72 \mathrm{~h}$ of culture were measured in the conditioned medium.

\section{Influence of $17 \beta$-estradiol on the effect of thyroid hormone}

To examine the possible influence of estrogen on the effect of thyroid hormone on basal and IL-1-stimulated IL-6/IL-11 production, the cells were treated with $17 \beta$ estradiol $\left(10^{-8} \mathrm{M}\right)$ for $24 \mathrm{~h}$ before the addition of $\mathrm{T}_{3}$ and/or IL-1. The results were compared with those from groups not treated with estrogen in the same set of experiments.

\section{Statistics}

All experiments were repeated at least three times using different hBMSC preparations, and representative data are shown in the figures. The significance of the differences between treatment groups was assessed using the MannWhitney U-test or ANOVA and post-hoc analysis with Duncan's multiple range test as appropriate. Doseresponse relationships were examined by Spearman's rank correlation analysis.

\section{Results}

Effect of $T_{3}$ on basal IL-6 and IL-11 production by hBMSCS

Treatment with $\mathrm{T}_{3}$, over the concentration range $10^{-12}$ $10^{-8} \mathrm{M}$, significantly increased hBMSC IL-6 production in a dose-dependent manner (Fig. 1A). $\mathrm{rT}_{3}$, an inactive analog of $\mathrm{T}_{3}$, did not elicit a response at a dose of $10^{-8} \mathrm{M}$ (data not shown). 
A

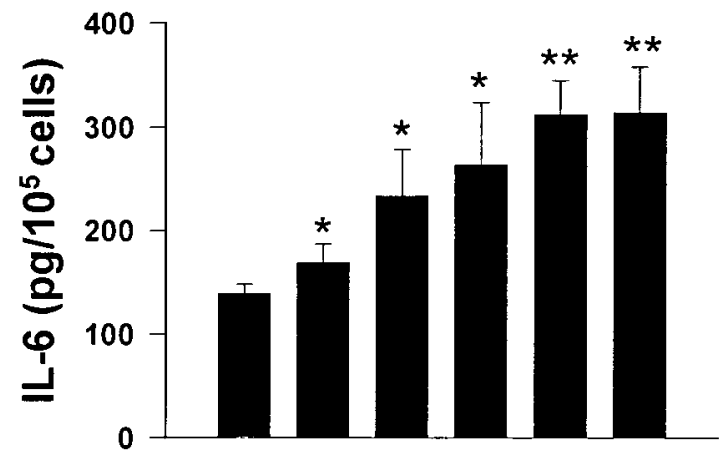

B

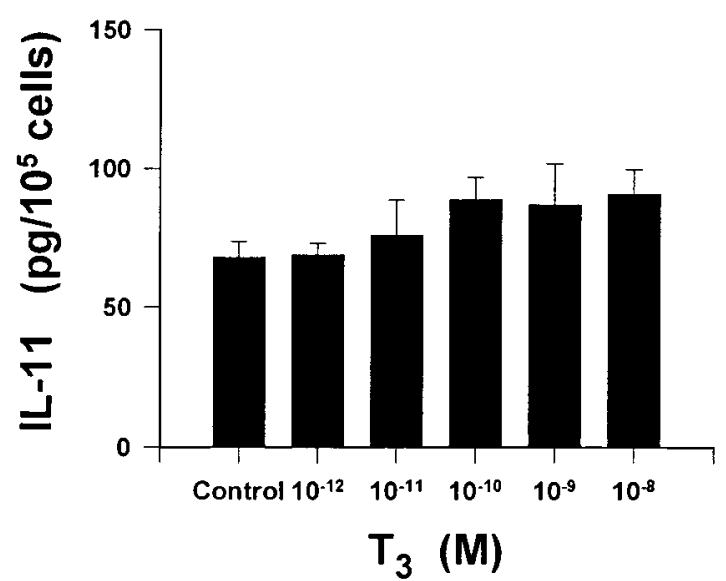

Figure 1 Effects of $T_{3}$ on basal IL-6 (A) and IL-11 (B) production in hBMSCs. Cells were treated with various concentrations of $T_{3}$ for $72 \mathrm{~h}$, and the amount of IL-6/IL-11 produced in the medium was expressed relative to the number of cells in each well. Values are means \pm S.D. $(n=6) .{ }^{*} P<0 \cdot 05,{ }^{*} P<00 \cdot 01$ vs control.

In contrast, $\mathrm{T}_{3}$ had no detectable effect on IL-11 production (Fig. 1B).

\section{Effect of $T_{3}$ on IL-1-stimulated IL-6 and IL-11 production} by hBMSCs

As previously reported (Kim et al. 1997b), IL-1 (10$1000 \mathrm{U} / \mathrm{ml}$ ) dose-dependently stimulated both IL-6 and IL-11 production in hBMSCs. $\mathrm{T}_{3}\left(10^{-8} \mathrm{M}\right)$ additively increased the IL-1-induced IL- 6 production at various concentrations of IL-1 (Fig. 2A). However, IL-1-induced IL-11 production was not affected by $\mathrm{T}_{3}$ treatment (Fig. 2B).

\section{Influence of $17 \beta$-estradiol on the effect of thyroid hormone}

Treatment with $17 \beta$-estradiol $\left(10^{-8} \mathrm{M}\right)$ inhibited IL-1induced IL- 6 production, but not $\mathrm{T}_{3}$-stimulated IL-6 production (Fig. 3A). IL-6 production co-stimulated by $\mathrm{T}_{3}$ and IL- 1 was partially inhibited by $17 \beta$-estradiol, but it was still greater than that stimulated by $\mathrm{T}_{3}$ or IL-1 alone.
A

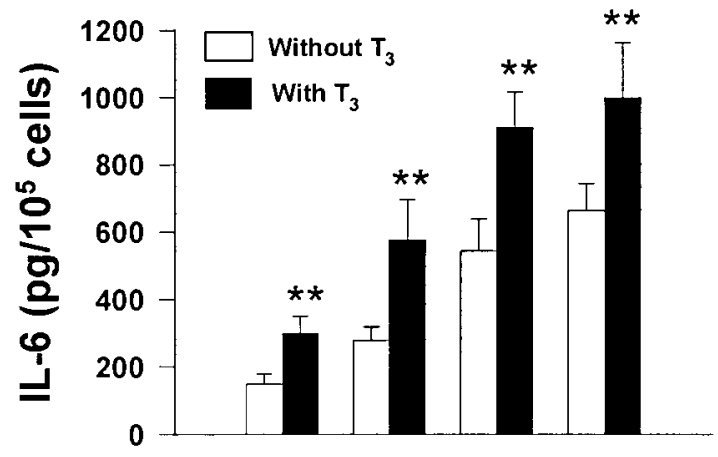

B

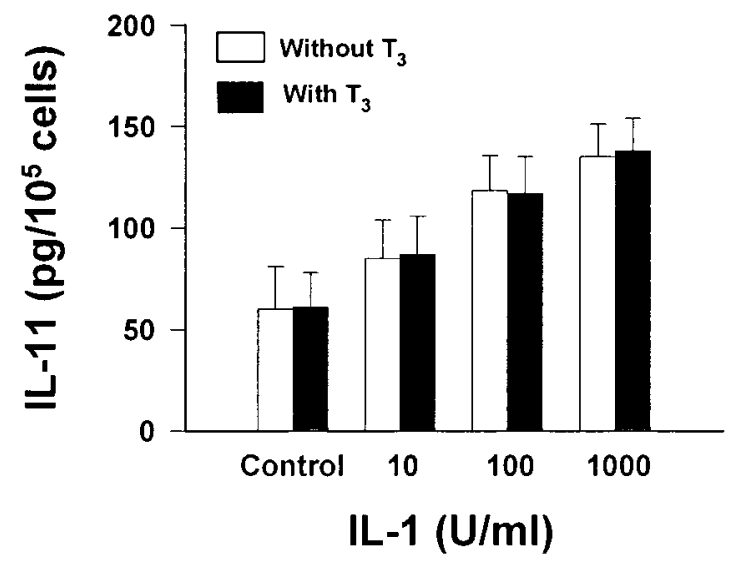

Figure 2 Effects of $\mathrm{T}_{3}$ on IL-1-induced IL-6 (A) and IL-11 (B) production in hBMSCs. Cells were stimulated with IL-1

$(10-1000 \mathrm{U} / \mathrm{ml})$ with or without $\mathrm{T}_{3}\left(10^{-8} \mathrm{M}\right)$, and the amounts of IL-6/IL-11 produced during $72 \mathrm{~h}$ were measured in the medium.

Values are means \pm S.D. $(n=6) .{ }^{* *} P<0 \cdot 01$ vs group without $T_{3}$.

There was no significant difference in IL-11 production in the presence or absence of $17 \beta$-estradiol (Fig. 3B).

\section{Discussion}

In the present study, $\mathrm{T}_{3}$ significantly increased basal and IL-1-stimulated IL-6 production in hBMSCs. These results support the possibility that increased IL-6 production by osteoblast-lineage cells plays an important role in thyroid hormone-induced bone loss. In line with this possibility, Lakatos et al. (1997) reported that serum IL-6 concentrations are elevated in patients with hyperthyroidism, and blood mononuclear cells derived from hyperthyroid patients secrete more IL-6 than those taken from healthy subjects. They also showed that bone turnover is increased and radius bone mineral content is reduced in patients with hyperthyroidism. Our results are also consistent with the report of Siddiqi et al. (1998) demonstrating that $\mathrm{T}_{3}$ increased both secretion and mRNA expression of IL- 6 and IL-8 by hBMSCs and MG63 osteoblast-like cell lines. 

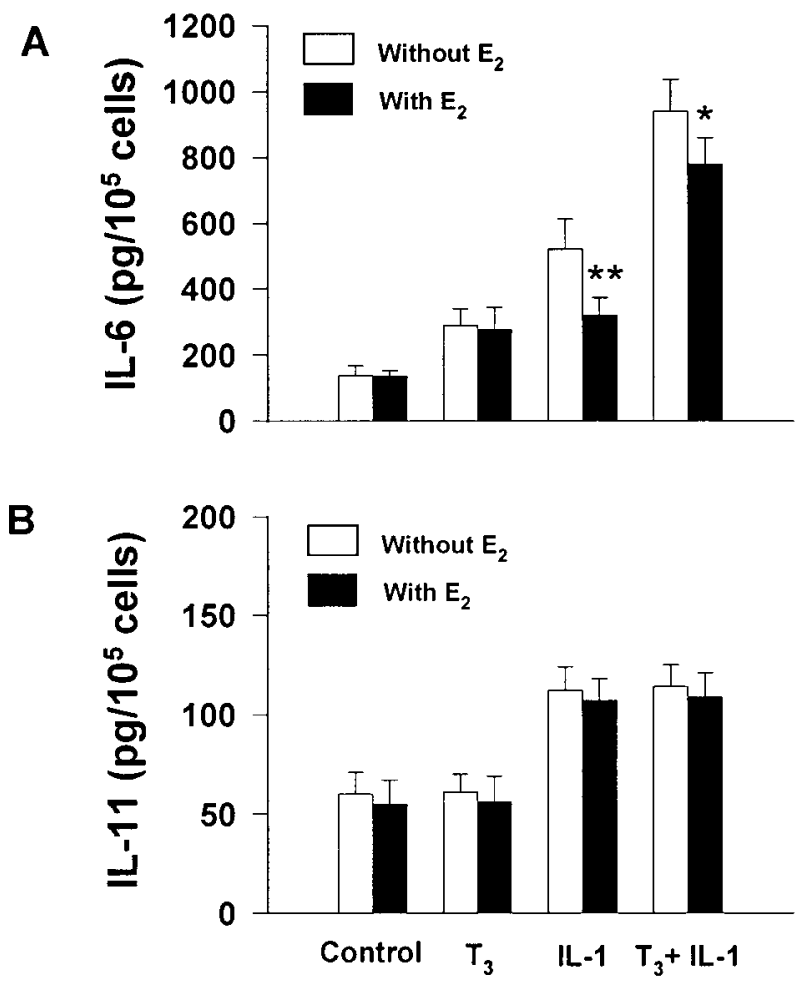

Figure 3 Effects of $17 \beta$-estradiol $\left(\mathrm{E}_{2}\right)$ on $\mathrm{T}_{3}$ and/or IL-1-stimulated IL-6 (A) and IL-11 (B) production in hBMSCs. The cells were treated with $17 \beta$-estradiol $\left(10^{-8} \mathrm{M}\right)$ for $24 \mathrm{~h}$ before the addition of $\mathrm{T}_{3}\left(10^{-8} \mathrm{M}\right)$ and/or IL-1 $(1000 \mathrm{U} / \mathrm{ml})$. The amounts of IL-6/IL-11 produced during $72 \mathrm{~h}$ were compared with those in groups not treated with estrogen. Values are means \pm S.D. $(n=6)$. ${ }^{*} P<0 \cdot 05,{ }^{*} P<0 \cdot 01$ vs group without $\mathrm{E}_{2}$.

Tarjan \& Stern $(1994,1995)$ reported that $\mathrm{T}_{3}$ potentiated the stimulatory effect of IL-1 on IL-6 production in neonatal mouse calvarial osteoblasts and fetal rat limb bone cultures, which is in agreement with our results with hBMSCs. However, our results show that $\mathrm{T}_{3}$ alone significantly increased basal IL-6 production. Tarjan \& Stern (1995) failed to observe the stimulatory effect in fetal rat limb bone culture of $\mathrm{T}_{3}$ on basal IL- 6 production over a $10^{-11}-10^{-6} \mathrm{M}$ concentration range. They observed that $\mathrm{T}_{3}$ alone increased ${ }^{45} \mathrm{Ca}$ release significantly only at a fairly high concentration $\left(10^{-6} \mathrm{M}\right)$, but in the presence of IL-1, $10^{-8} \mathrm{M} \mathrm{T}_{3}$ significantly potentiated the IL-1 effect on ${ }^{45} \mathrm{Ca}$ release. Treatment with IL-1 receptor antagonist blocked the potentiating effects of $\mathrm{T}_{3}$. They therefore speculated that the enhancement of IL-1-induced IL-6 production might be a biologically relevant mechanism of thyroid hormone-induced bone loss. On the other hand, our data showed that $T_{3}$, in the absence of IL-1, also directly stimulated IL-6 production. The reason for this discrepancy is not clear, but may be related to the difference in species of cell origin or stage of osteoblast phenotype expression (Williams et al. 1994). It has also been suggested that the presence/absence or relative levels of various forms of thyroid hormone receptor $\left(\alpha, \beta_{1}, \beta_{2}\right)$ in osteoblastic cells may explain the variability of the response to thyroid hormone (Suwanwalaikorn et al. 1997). Alternatively, we cannot exclude the possibility that endogenous IL-1 production is higher in human than rat bone cell cultures. However, it was reported that human bone marrow stromal cells did not constitutively produce significant amounts of IL-1 $\beta$, although low levels of expression of IL-1 $\beta$ mRNA were detected (Aman et al. 1994).

Our results show that the effect of thyroid hormone on IL-6 production was not affected by estrogen. Consistent with this, Lakatos et al. (1997) observed that there was no difference in pre- and post-menopausal IL-6 levels in hyperthyroid patients. Taken together, the results suggest that thyroid hormone and estrogen act via different mechanisms in regulating IL-6 production. A recent meta-analysis report showed that suppressive doses of thyroid hormone therapy had a detrimental effect on all skeletal sites in postmenopausal women, whereas it had little effect in premenopausal women (Uzzan et al. 1996). Our experimental data and those of others (Tarjan \& Stern 1994, 1995) showing the synergistic effect of thyroid hormone and IL-1, which is increased in the estrogendeficient state, on IL-6 secretion may explain this phenomenon. However, further studies are needed to clarify this controversial issue.

IL-11 is a fairly recently discovered cytokine which has a role in osteoclast development (Girasole et al. 1994). The effects of thyroid hormone on IL-11 secretion have not yet been studied. We observed in this study that neither basal nor IL-1-induced IL-11 production is affected by thyroid hormone. However, we cannot exclude the possibility that thyroid hormone affects IL-11 production synergistically with other systemic or local cofactors (Manolagas 1995, Kim et al. 1997b) that exist in vivo.

In this study, $\mathrm{T}_{3}$ had a detectable effect on IL6 secretion at concentrations much lower than those found in human plasma (about $10^{-9} \mathrm{M}$ ). Under the experimental conditions used, free hormone concentrations in the medium may be higher than those found in vivo, as culture medium containing 5\% serum would contain less $\mathrm{T}_{3^{-}}$ binding protein than in vivo. At present, however, the physiological implication of this finding is difficult to clarify even if we measure the free $T_{3}$ concentrations in the culture medium, because the local thyroid hormone concentration to which bone cells are exposed in vivo may be different from the circulating concentration. Further studies are needed.

It should be pointed out that the hBMSCs used in this study are not mature osteoblasts. However, previous studies have shown that, when cultured to confluence in the presence of serum, these cells possess many of the phenotypic characteristics of differentiated osteoblasts, including deposition of mineralized matrix (Kassem et al. 1991, Cheng et al. 1994). They produce type I procollagen 
and osteocalcin in response to 1,25-dihydroxyvitamin $\mathrm{D}_{3}$ (Kassem et al. 1991) and also increase cAMP in response to parathyroid hormone (Cheng et al. 1994). We also confirmed that these cells deposit calcium in the extracellular matrix, and express mRNA characteristic of osteoblastic cells, such as alkaline phosphatase, $\alpha 1(\mathrm{I})$ collagen, osteopontin, and decorin (Kim et al. 1997a). Another possible limitation of using these cells is that they may exhibit heterogeneity between samples because of different proportions of preosteogenic, preadipogenic and prechondrogenic cell precursors. However, this should not be a significant problem because we cultured the cells under the same standardized conditions and we repeated the experiments at least three times using different hBMSC preparations to confirm the consistency of the results.

In conclusion, these results suggest that thyroid hormone may increase bone resorption by stimulating osteoclast formation and activity by increasing basal and IL-1-induced IL-6 production by osteoblastic cells.

\section{Acknowledgements}

The authors wish to acknowledge the financial support of the Korea Research Foundation in the program year of 1997. The result of this work was presented as an abstract at the 19th Annual Meeting of the American Society for Bone and Mineral Research, Cincinnati, USA, September 1997.

\section{References}

Allain TJ \& McGregor AM 1992 Thyroid hormones and bone. Journal of Endocrinology 139 9-18.

Allain TJ, Chambers TJ, Flanagan AM \& McGregor AM 1992 Triiodothyronine stimulates rat osteoclastic bone resorption by an indirect effect. Journal of Endocrinology 133 327-331.

Allain TJ, Yen PM, Flanagan AM \& McGregor AM 1996 The isoform-specific expression of the tri-iodothyronine receptor in osteoblasts and osteoclasts. European Journal of Clinical Investigation 26 418-425.

Aman MJ, Keller U, Derigs G, Mohamadzadeh M, Huber C \& Peschel C 1994 Regulation of cytokine expression by interferon- $\alpha$ in human bone marrow stromal cells: inhibition of hematopoietic growth factors and induction of interleukin-1 receptor antagonist. Blood 84 4142-4150.

Bordier P, Miravet L, Matrajt H, Hioco D \& Ryckewaert A 1967 Bone changes in adult patients with abnormal thyroid function. Proceedings of the Royal Society of Medicine 60 1132-1134.

Britto JM, Fenton AJ, Holloway WR \& Nicholson GC 1994 Osteoblasts mediate thyroid hormone stimulation of osteoclastic bone resorption. Endocrinology 134 169-176.

Cheng SL, Yang JW, Rifas L, Zhang S-F \& Avioli LV 1994 Differentiation of human bone marrow osteogenic stromal cells in vitro: induction of the osteoblast phenotype by dexamethasone. Endocrinology 134 277-286.

Cummings SR, Nevitt MC, Browner WS, Stone K, Fox KM, Ensrud KE, Cauley J, Black D \& Vogt TM 1995 Risk factors for hip fracture in white women. New England Journal of Medicine 332 $767-773$.
Diamond T, Nery N \& Hales I 1991 A therapeutic dilemma: suppressive doses of thyroxine significantly reduce bone mineral measurements in both premenopausal and postmenopausal women with thyroid carcinoma. Journal of Clinical Endocrinology and Metabolism 72 1184-1188.

Girasole G, Jilka RL, Passeri G, Boswell S, Boder G, Williams DC \& Manolagas SC 1992 17 $\beta$-Estradiol inhibits interleukin-6 production by bone marrow-derived stromal cells and osteoblasts in vitro: a potential mechanism for the antiosteoporotic effect of estrogens. Journal of Clinical Investigation 89 883-891.

Girasole G, Passeri G, Jilka RL \& Manolagas SC 1994 Interleukin-11: a new cytokine critical for osteoclast development. Journal of Clinical Investigation 93 1516-1524.

Harvey RD, McHardy KC, Reid IW, Paterson F, Bewsher PD, Duncan A \& Robins SP 1991 Measurement of bone collagen degradation in hyperthyroidism and during thyroxine replacement therapy using pyridinium cross-links as specific urinary markers. Journal of Clinical Endocrinology and Metabolism 72 1189-1194.

Hoffmann O, Klaushofer K, Koller K, Peterlik M, Mavreas T \& Stern P 1986 Indomethacin inhibits thrombin-, but not thyroxinestimulated resorption of fetal rat limb bones. Prostaglandins $\mathbf{3 1}$ 601-608.

Kasono K, Sato K, Han DC, Fujii Y, Tsushima T \& Shizume K 1988 Stimulation of alkaline phosphatase activity by thyroid hormone in mouse osteoblast-like cells (MC3T3-E1): a possible mechanism of hyperalkaline phosphatasia in hyperthyroidism. Bone and Mineral 4 355-363.

Kassem M, Risteli L, Mosekilde L, Melsen F \& Eriksen EF 1991 Formation of osteoblast-like cells from human mononuclear bone marrow cultures. APMIS 99 269-274.

Kassem M, Mosekilde L \& Eriksen EF 1993 Effects of triiodothyronine on DNA synthesis and differentiation markers of normal human osteoblast-like cells in vitro. Biochemistry and Molecular Biology International 30 779-788.

Kim C-H, Cheng S-L \& Kim GS 1997a Lack of autocrine effects of IL-6 on human bone marrow stromal osteoprogenitor cells. Endocrine Research 23 181-190.

Kim GS, Kim C-H, Park JY, Lee K-U \& Park CS 1996 Effects of vitamin $\mathrm{B}_{12}$ on cell proliferation and cellular alkaline phosphatase activity in human bone marrow stromal osteoprogenitor cells and UMR106 osteoblastic cells. Metabolism 45 1443-1446.

Kim GS, Kim C-H, Choi CS, Park JY \& Lee K-U 1997 b Involvement of different second messengers in parathyroid hormone- and interleukin-1-induced interleukin-6 and interleukin-11 production in human bone marrow stromal cells. Journal of Bone and Mineral Research 12 896-902.

Klaushofer K, Hoffmann O, Gleispach H, Leis H-J, Czerwenka E, Koller K \& Peterlik M 1989 Bone-resorbing activity of thyroid hormones is related to prostaglandin production in cultured neonatal mouse calvaria. Journal of Bone and Mineral Research 4 305-312.

Lakatos P, Foldes J, Horvath C, Kiss L, Tatrai A, Takacs I, Tarjan G \& Stern PH 1997 Serum interleukin-6 and bone metabolism in patients with thyroid function disorders. Journal of Clinical Endocrinology and Metabolism 82 78-81.

LeBron BA, Pekary AE, Mirell C, Hahn TJ \& Hershman JM 1989 Thyroid hormone 5'-deiodinase activity, nuclear binding, and effects on mitogenesis in UMR-106 osteoblastic osteosarcoma cells. Journal of Bone and Mineral Research 4 173-178.

Lee MS, Kim SY, Lee MC, Cho BY, Lee HK, Koh CS \& Min HK 1990 Negative correlation between the change in bone mineral density and serum osteocalcin in patients with hyperthyroidism. Journal of Clinical Endocrinology and Metabolism 70 766-770.

Manolagas SC 1995 Role of cytokines in bone resorption. Bone 17 63S-67S. 
Mosekilde L \& Melsen F 1978 A tetracycline-based histomorphometric evaluation of bone resorption and bone turnover in hyperthyroidism and hyperparathyroidism. Acta Medica Scandinavica 204 97-102.

Mundy GR, Shapiro JL, Bandelin JG, Canalis EM \& Raisz LG 1976 Direct stimulation of bone resorption by thyroid hormones. Journal of Clinical Investigation 58 529-534.

Rizzoli R, Poser J \& Burgi U 1986 Nuclear thyroid hormone receptors in cultured bone cells. Metabolism 35 71-74.

Siddiqi A, Burrin JM, Wood DF \& Monson JP 1998 Triiodothyronine regulates the production of interleukin- 6 and interleukin-8 in human bone marrow stromal and osteoblast-like cells. Journal of Endocrinology 157 453-461.

Suwanwalaikorn S, Auken MV, Kang M-I, Alex S, Braverman LE \& Baran DT 1997 Site selectivity of osteoblast gene expression response to thyroid hormone localized by in situ hybridization. American Journal of Physiology 272 E212-E217.

Tarjan G \& Stern PH 1994 Triiodothyronine up-regulates the stimulatory effect of interleukin- $1 \beta$ on interleukin- 6 production in mouse osteoblasts and fetal rat limb bones. Journal of Bone and Mineral Research 9 (Suppl 1) C266 (Abstract).
Tarjan G \& Stern PH 1995 Triiodothyronine potentiates the stimulatory effects of interleukin- $1 \beta$ on bone resorption and medium interleukin-6 content in fetal rat limb bone cultures. Journal of Bone and Mineral Research 10 1321-1326.

Toh SH, Claunch BC \& Brown PH 1985 Effect of hyperthyroidism and its treatment on bone mineral content. Archives of Internal Medicine 145 883-886.

Uzzan B, Campos J, Cucherat M, Nony P, Boissel JP \& Perret GY 1996 Effects on bone mass of long term treatment with thyroid hormones: a meta-analysis. Journal of Clinical Endocrinology and Metabolism 81 4278-4289.

Williams GR, Bland R \& Sheppard MC 1994 Characterization of thyroid hormone $\left(\mathrm{T}_{3}\right)$ receptors in three osteosarcoma cell lines of distinct osteoblast phenotype: interactions among $\mathrm{T}_{3}$, vitamin $\mathrm{D}_{3}$, and retinoid signaling. Endocrinology 135 $2375-2385$

Received 8 June 1998

Accepted 1 September 1998 